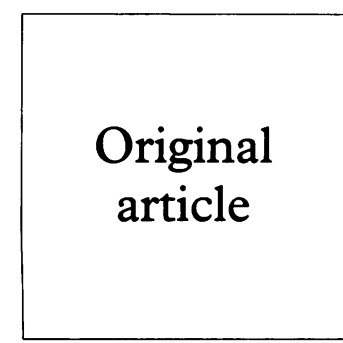

\title{
PCR for detection of Chlamydia trachomatis in endocervical, urethral, rectal, and pharyngeal swab samples obtained from patients attending an STD clinic
}

\author{
Lars Østergaard, Tove Agner, Elizabeth Krarup, Urs B Johansen, Kaare Weismann, \\ Ernö Gutschik
}

Objective: To investigate, by use of the Amplicor PCR in a routine setting, the recovery rate of Chlamydia trachomatis in ano-rectal and pharyngeal swab samples obtained from males and females attending an STD clinic in relation to sexual practices, symptoms, and signs.

Design: Data regarding sexual practices, and symptoms and signs related to the rectum and pharynx, were obtained from 196 females and 208 males, including 31 homosexuals and eight bisexuals. Swab samples were obtained from the urethra, rectum, and pharynx from all the patients. An additional endocervical swab sample was obtained from the females.

Methods: All samples were analysed by the Amplicor PCR (Roche).

Setting: Rudolph Bergh's Hospital, a clinic for sexually transmitted diseases situated in the centre of Copenhagen, Denmark.

Results: The overall prevalence of urogenital $C$ trachomatis infection was $9 \cdot 2 \%(37 / 404)$. The specificity of the Amplicor PCR was $100 \%$ for both ano-rectal and pharyngeal swab samples. In females three $(13 \%)$ of the 23 infections were detected only by testing an ano-rectal or throat swab sample. In homosexual males two (67\%) of three infections were detected only by the anorectal swab sample. Ano-rectal intercourse without use of condom was reported by $44 \%$ of females and by $52 \%$ of homosexual males. Fellatio without condom use was reported by $91 \%$ of females, and $80 \%$ of heterosexual males practised cunnilingus. Pharyngeal infection, however, occurred only in females, and the presence of pharyngeal symptoms or signs seemed predictive for pharyngeal $C$ trachomatis infection, for which the time of incubation or colonisation exceeded 3 months. The presence of ano-rectal signs or symptoms was not predictive for an ano-rectal $C$ trachomatis infection.

Conclusion: The Amplicor PCR can be used on ano-rectal and pharyngeal swab samples. Anorectal swab samples should be obtained in females and homosexual males at high risk of being infected. Pharyngeal samples should be taken in females at high risk of being infected, especially when pharyngeal signs or symptoms are present.

(Genitourin Med 1997;73:493-497)

Department of Infectious Diseases, Aarhus University Hospital, PP Orumsgade 11, DK8000 Aarhus C, Denmark

L Østergaard

Department of Dermato-Venerology, University of Copenhagen, Bispebjerg Hospital, Bispebjerg Bakke 23, 2400 Copenhagen NV, Denmark

T Agner

U B Johansen

K Weismann

Department of Clinical Microbiology,

University of

Copenhagen,

Bispebjerg Hospital,

Bispebjerg Bakke 23,

2400 Copenhagen NV, Denmark

E Krarup

E Gutschik

Correspondence to: Lars Østergaard, MD, PhD, Department of Infectious Diseases, Aarhus University Hospital, PP Ørumsgade 11, DK-8000 Aarhus C,

Denmark.

Accepted for publication 8 July 1997

Keywords: polymerase chain reaction; Chlamydia trachomatis; swab samples

\section{Introduction}

Chlamydia trachomatis is the leading cause of bacterial sexually transmitted diseases. The organism is detected in urethral or endocervical swab specimens in about $10 \%$ of patients attending sexually transmitted disease clinics. ${ }^{1}$ The infection is often asymptomatic, ${ }^{12}$ and may cause serious complications. ${ }^{3}$ But if recognised it is easily treated with a single dose of azithromycin. ${ }^{4}$ Sensitive diagnostic tests such as the DNA amplification tests are therefore needed.

In addition to effective diagnostic tests, effective examination of patients is also needed in order to obtain epidemic disease control and to avoid reinfection. This may include examination of potentially $C$ trachomatis infected anatomical sites that may be overlooked when only samples from the urethra and endocervix are analysed-that is, examination of the ano-rectal and pharyngeal region may increase the diagnostic efficacy.
By use of cell culture, $C$ trachomatis has been recovered from the pharynx in $3.5 \%{ }^{5}$ of examined females, and from the rectum in $5 \%^{5}$ and $4-8 \%^{6-10}$ of females and homosexual males, respectively. The sensitivity of the polymerase chain reaction (PCR) is theoretically superior to that of cell culture, and use of PCR may therefore increase the recovery rate of $C$ trachomatis from ano-rectal and pharyngeal swabs. PCR has been used on ano-rectal and pharyngeal samples in only a few studies. Workowski et al ${ }^{11}$ examined ano-rectal swab samples from $20 C$ trachomatis infected females and found 13 PCR positives, and Jebakumar et al ${ }^{12}$ found recovery rates of $2 \cdot 4 \%$ and zero in 124 pharyngeal swab samples by use of PCR and cell culture, respectively. Kessler et $a l^{13}$ also found that PCR was superior to cell culture on pharyngeal swabs.

With the increasing routine use of DNA amplification methods it is important to assess the diagnostic efficacy of these test systems on 
pharyngeal and ano-rectal swab samples. The use of self obtained samples for detection of urogenital $C$ trachomatis infection ${ }^{14-16}$ may also be extended in the future. Such diagnostic strategy, however, may overlook ano-rectal and pharyngeal $C$ trachomatis infections. It is therefore pertinent to investigate the clinical features that could predict patients in whom additional pharyngeal and/or ano-rectal swab samples should be obtained.

The purpose of the present study was therefore to assess the recovery of $C$ trachomatis from the rectum and pharynx by use of PCR, and to assess sexual practices, and signs and symptoms as predictors for ano-rectal and pharyngeal colonisation.

\section{Patients and methods PATIENTS}

Patients were enrolled from December 1995 to July 1996 among attenders at the Rudolph Bergh Hospital, a clinic for sexually transmitted diseases in the centre of Copenhagen, Denmark. After written informed consent, a standard questionnaire about sexual behaviour and symptoms was completed by every patient. During the following examination, swab samples from the endocervix (in females), urethra, rectum, and tonsils/pharynx were obtained from every patient. Patients who had received antibiotics within 4 weeks before examination were not included.

SAMPLES OBTAINED FOR C TRACHOMATIS DETECTION BY THE AMPLICOR PCR

The endocervical and urethral swab samples were obtained according to the package insert information in the Amplicor Chlamydia trachomatis kit (Roche Molecular Systems). The ano-rectal sample was obtained by introducing the short Amplicor (Roche) swab $5 \mathrm{~cm}$ into the rectum under rotating movements three times. The sampling procedure was designed to involve the ano-rectal junction zone. The pharyngeal swab sample was obtained by use of the short Amplicor (Roche) swab by wiping it twice over each tonsil and afterwards once on the pharyngeal wall. Swabs from each anatomical region were placed in Amplicor transport medium (Roche). Samples for $C$ trachomatis detection were obtained before samples for detection of Neisseria gonorrhoeae. All swab samples were transported from the STD clinic to the department of clinical microbiology as recommended by the manufacturer.

CLINICAL EXAMINATIONS

Urethral smears from males with symptoms or signs of urethral discharge were examined under the microscope. Urethritis was diagnosed when abnormal urethral discharge was reported or seen during examination and an average of more than four polymorphonuclear leucocytes per field were counted in three fields at a magnification of $\times 1000$. An endocervical smear was taken from females who reported discharge, and mucopurulent cervicitis was diagnosed when: (i) there was no sign of Candida by microscopy, or Trichomonas by culture or microscopy, (ii) an average of more than 20 polymorphonuclear leucocytes per field were counted in three fields at a magnification of $\times 1000$, and (iii) at least two of the three following were present: changed vaginal discharge; purulent or mucopurulent secretion from the orifice; and vulnerable endocervical mucosa. The presence of ano-rectal and/or pharyngeal inflammation was judged by the venereologist.

MICROBIOLOGICAL ANALYSES

All analyses for $C$ trachomatis DNA were performed consecutively in a routine setting at the Department of Clinical Microbiology, Bispebjerg Hospital, Denmark, by use of the Amplicor Chlamydia trachomatis PCR according to the manufacturer's instructions for swab samples. The PCR testing was performed twice a week, so the maximum storage for samples was 4 days, during which period they were refrigerated. All PCR positive samples were retested by use of the unfrozen prepared sample material in the next routine PCR runthat is, within 4 days.

Swab samples for detection of $N$ gonorrhoeae were obtained from the endocervix, urethra, rectum, and tonsils; they were analysed by conventional culture methods.

\section{SPECIFICITY OF PCR ON SWAB SAMPLES} OBTAINED FROM RECTUM AND PHARYNX Ano-rectal swab samples obtained from heterosexual males comprised the group in which the specificity of PCR on rectal samples was assessed. Pharyngeal swab samples from males who did not report cunnilingus, and pharyngeal swab samples from females who did not report fellatio, comprised the group in which the specificity of PCR on pharyngeal samples was assessed.

\section{DEFINITION OF INFECTION}

A patient was considered infected with $C$ trachomatis if a swab sample was repeatedly positive by the Amplicor PCR.

\section{STATISTICS}

The $\chi^{2}$ test or Fisher's exact test were used, as appropriate, for categorical data.

\section{ETHICS}

The study was approved by the local ethics committee of Copenhagen and Frederiksberg's county council.

\section{Results}

SPECIFICITY OF THE PCR ON THE ANO-RECTAI AND THROAT SWAB SAMPLES

The ano-rectal swab sample was negative in all 169 heterosexual males (table 1). Thus, the specificity of ano-rectal swab samples was considered to be $100 \%$.

The pharyngeal sample was negative in all 17 women who had never practised fellatio and in all 33 heterosexual males who had never practised cunnilingus, and the specificity of pharyngeal samples was thus assumed to be $100 \%$. 
Table 1 Observed combinations of results from various anatomical sampling sites

\begin{tabular}{lllllc}
\hline & $\begin{array}{l}\text { Endocervical } \\
\text { swab sample }\end{array}$ & $\begin{array}{l}\text { Urethral } \\
\text { swab sample }\end{array}$ & $\begin{array}{l}\text { Ano-rectal } \\
\text { swab sample }\end{array}$ & $\begin{array}{l}\text { Pharyngeal } \\
\text { swab sample }\end{array}$ & $\begin{array}{l}\text { No of } \\
\text { patients }\end{array}$ \\
\hline Heterosexual females & + & + & + & + & 1 \\
& + & + & + & - & 4 \\
& + & + & - & - & 5 \\
& + & - & + & - & 5 \\
& - & + & + & - & 1 \\
Homosexual males & - & - & - & + & 1 \\
& - & - & + & - & 1 \\
Bisexual males & NA & - & - & - & 1 \\
Heterosexual males & NA & - & - & - & 173 \\
& NA & - & - & - & 2 \\
& NA & + & - & - & 8 \\
& NA & - & - & - & 11 \\
\hline
\end{tabular}

NA $=$ not applicable. whom $(28.6 \%)$ had a $C$ trachomatis infection. All four females had positive endocervical swab samples (data not shown).

Eighty six (44\%) of the 196 females reported ano-rectal intercourse without condom use, and $27(14 \%)$ had practised this within the 3 months before inclusion. Of these 86 females, four had a positive ano-rectal swab sample (table 2). But among the 110 females who had never practised unprotected ano-rectal intercourse, seven had a positive ano-rectal swab sample. Neither ano-rectal symptoms nor ano-rectal signs were predictive for a positive ano-rectal swab sample (data not shown).

Fellatio without condom use was reported by $179(91 \%)$ of whom three had a positive pharyngeal swab sample. These three patients had not practised unprotected fellatio within the 3 months before the examination (table 2). Twenty three females $(12 \%)$ reported pharyngeal symptoms; four (17\%) were infected, including two females with a positive pharyngeal swab sample. Nine $(5 \%)$ of the 196 females had abnormal pharyngeal signs, and three of these $(33 \%)$ had a $C$ trachomatis infection, including one patient with a positive pharyngeal swab sample (Fisher's exact test, NS).

\section{HETEROSEXUAL MALES}

A total of 169 heterosexual males aged 19-58 years (mean: 32 years) were enrolled, of whom $11(7 \%)$ were positive for $C$ trachomatis. Eleven males reported an intimate relationship with a $C$ trachomatis infected female within the 3 months before examination, but none of them was infected. This contrasts with the rate of transmission found for females, in whom $43 \%(6 / 14)$ were infected (Fisher's exact test, $\mathrm{p}=0.03)$.

Despite a rate of cunnilingus of $80 \%(64 \%$ within the 3 months before examination) and a rate of pharyngeal symptoms and signs of $8 \%$ and $2 \%$, respectively, all 169 pharyngeal swab samples were negative (data not shown).

\section{BISEXUAL MALES}

Eight bisexual males were included. None had any positive test.

\section{HOMOSEXUAL MALES}

Thirty one homosexual males aged 20-67 years (mean 34.7 years) were enrolled. Three (10\%) were infected with $C$ trachomatis. Nine

Table 2 Clinical features in relation to positive anatomical sampling site in heterosexual females

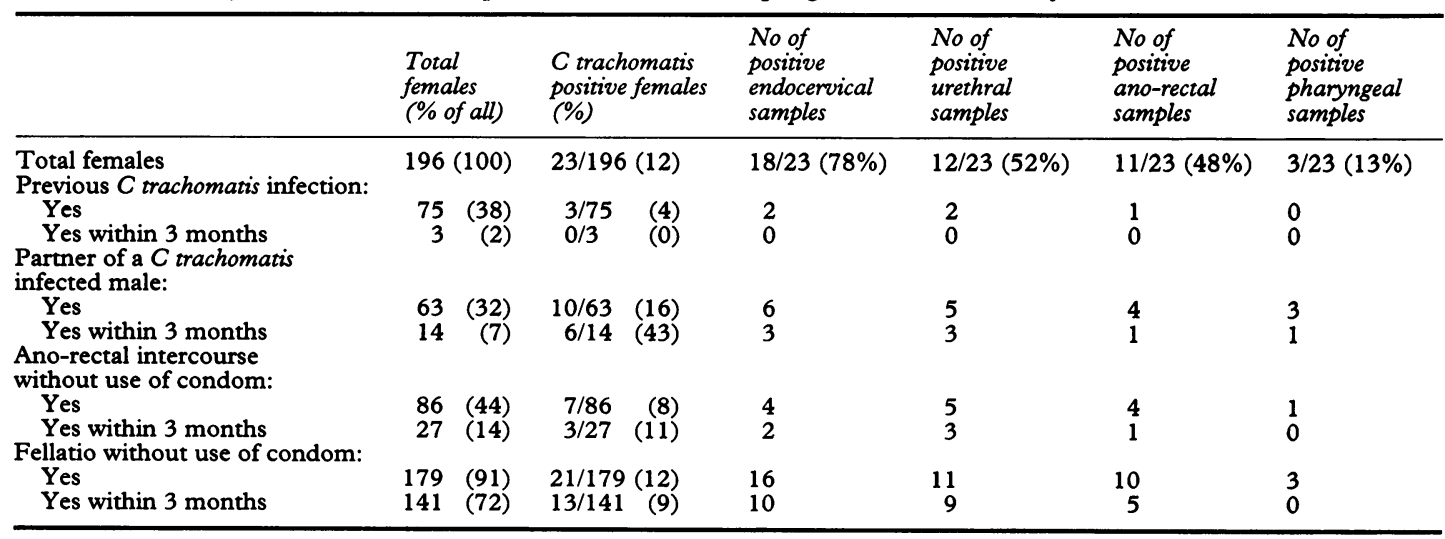


Table 3 Clinical features in relation to positive anatomical sampling site in homosexual males

\begin{tabular}{|c|c|c|c|c|c|}
\hline & $\begin{array}{l}\text { Total } \\
\text { homosexual } \\
\text { males } \\
\text { (\% of all) }\end{array}$ & $\begin{array}{l}C \text { trachomatis } \\
\text { positive } \\
\text { homosexual } \\
\text { males (\%) }\end{array}$ & $\begin{array}{l}\text { No of } \\
\text { positive } \\
\text { urethral } \\
\text { samples }\end{array}$ & $\begin{array}{l}\text { No of } \\
\text { positive } \\
\text { ano-rectal } \\
\text { samples }\end{array}$ & $\begin{array}{l}\text { No of } \\
\text { positive } \\
\text { pharyngeal } \\
\text { samples }\end{array}$ \\
\hline Total homosexual males & $31(100)$ & $3 / 31(10)$ & $1 / 3(33 \%)$ & $2 / 3(67 \%)$ & $0 / 23(0 \%)$ \\
\hline $\begin{array}{l}\text { Previous } C \text { trachomatis infection: } \\
\text { Yes }\end{array}$ & & & & & \\
\hline $\begin{array}{l}\text { Yes } \\
\text { Yes within } 3 \text { months }\end{array}$ & $\begin{array}{ll}2 & (7) \\
0 & (0)\end{array}$ & $\begin{array}{ll}0 / 2 & (0) \\
0 / 0 & (-)\end{array}$ & $\begin{array}{l}0 \\
0\end{array}$ & $\begin{array}{l}0 \\
0\end{array}$ & $\begin{array}{l}0 \\
0\end{array}$ \\
\hline $\begin{array}{l}\text { Partner of a } C \text { trachomatis } \\
\text { infected male: }\end{array}$ & & & & & \\
\hline Yes & (7) & $0 / 2 \quad(0)$ & 0 & 0 & 0 \\
\hline Yes within 3 months & (0) & $0 / 0$ & 0 & 0 & 0 \\
\hline $\begin{array}{l}\text { Ano-rectal intercourse } \\
\text { without use of condom: }\end{array}$ & & & & & \\
\hline Yes & $16 \quad(52)$ & $2 / 16(13)$ & 0 & 2 & 0 \\
\hline Yes within 3 months & $8(26)$ & $1 / 8$ (13) & 0 & 1 & 0 \\
\hline Fellatio without use of condom: & & & & & \\
\hline Yes & $26 \quad(84)$ & $2 / 26 \quad(8)$ & 1 & 1 & 0 \\
\hline Yes within 3 months & $22(71)$ & $2 / 22$ (9) & 1 & 1 & 0 \\
\hline
\end{tabular}

(29\%) reported more than five partners during the previous 6 months. One of these nine was infected with $C$ trachomatis.

Fifty two per cent $(16 / 31)$ reported being receptive partners of ano-rectal intercourse without use of condom $(26 \%$ within the 3 months before examination), and two of these were infected. For both patients the sample obtained from the rectum was the only positive sample (table 3 ). All rectal samples from the 15 males who had not had ano-rectal intercourse were negative. Twenty six $(84 \%)$ had practised unprotected fellatio but none of these had a positive pharyngeal swab sample (table 3).

NEISSERIA GONORRHOEAE

Samples for detection of $N$ gonorrhoeae were available from 194 of the 196 included females, and from 206 of the 208 males. One female had a positive cervical culture for $N$ gonorrhoeae, and she was also positive for $C$ trachomatis. Two males had positive cultures from the urethra. Both were homosexual and negative for $C$ trachomatis. All ano-rectal and pharyngeal samples were negative for $N$ gonorrhoeae.

\section{Discussion}

Our study demonstrates that the Amplicor PCR can be used on pharyngeal and ano-rectal swab samples; by including these samples, the diagnostic efficacy for detecting $C$ trachomatis infection was increased among females and homosexual males attending an STD clinic.

Compared with studies in which cell culture was the detection method, our recovery rates of ano-rectal infections in females and homosexual males, $5 \cdot 6 \%$ and $6.5 \%$, respectively, was somewhat lower than could be expected by use of the more sensitive PCR technique. ${ }^{6-10}$ This could be due to a lower prevalence of $C$ trachomatis infection in our population than in the populations studied by cell culture. There may also be a difference between the serotypes in the studied populations, since $C$ trachomatis serovar $F$ has revealed fewer ano-rectal infections in females, compared with other serotypes. ${ }^{17}$ Furthermore, inhibitors of the polymerase activity of the PCR may be present in the ano-rectal (and pharyngeal) swab samples, thereby giving a suboptimal sensitivity of PCR. In our study, however, we chose to evaluate the diagnostic performance of a commercially available PCR in a routine setting, and evaluation of inhibition was therefore not obtainable. An alternative procedure to evaluate the presence of inhibition could be to dilute specimens. However, if a sample contains a low copy number of Chlamydia organisms and a dilution is performed, the concentration of Chlamydia in the diluted sample may become lower than the detection limit of the test system and the result may still be negative despite the presence of Chlamydia DNA in the original sample. Thus, the activity of inhibitors may outweigh the number of organisms in the sample. In addition, testing for inhibition by dilution in a routine setting will have to be comprehensive since all specimens testing negative have then to be diluted and retested (that is, two or even more PCR tests should be performed on all negative specimens). New commercially available DNA amplification systems with an internal control may answer the questions concerning inhibition.

Ano-rectal swab samples were positive both in females who practised unprotected ano-rectal intercourse and in females who did not Knowing, from the 169 negative ano-rectal swab samples obtained from heterosexual males, that PCR has a high specificity on anorectal swab samples, the positive ano-rectal swab samples from females who had never been at risk may indicate auto-inoculation into the ano-rectal mucosa or colonisation of the ano-rectal region by $C$ trachomatis DNA. The latter explanation can be seen in the light of the fact that urine can be used to detect isolated endocervical infections. ${ }^{16}$

Despite the high frequency of unprotected ano-rectal intercourse among females and homosexual males, no correlation between symptoms and/or signs and ano-rectal infection was found. This is in agreement with the findings of Munday et al, ${ }^{9}$ who studied a population of homosexual males.

Three pharyngeal infections were found among females practising unprotected fellatio, but none was found among males practising cunnilingus. Although not statistically significant, this difference may indicate that the oro- 
penile transmission rate is higher than the orovaginal transmission rate. The difference may be explained by transmission of viable $C$ trachomatis organisms from semen or male urethra, and transmission of non-viable Chlamydia organisms, or lack of transmission, from the vaginal introitus. All the females with pharyngeal $C$ trachomatis infection had practised unprotected fellatio, but not during the 3 months before examination. This might indicate a chronic carrier state or an incubation time exceeding 3 months, and it stresses the importance of taking a pharyngeal swab sample in the presence of symptoms or signs, irrespective of the time after exposure.

The difference in the transmission rates of infection for females and heterosexual males, $43 \%$ and zero, respectively, contrasts with the findings by Quinn et $a l^{18}$ who by use of PCR found identical transmission rates for males and females. However, our observed difference in transmission rate is in accordance with findings by Worm and Petersen ${ }^{19}$ who used cell culture as the method of detection. There seems to be no obvious explanation for this phenomenon.

The proportions of females with cervicitis and males with urethritis in whom $C$ trachomatis or $N$ gonorrhoeae could not be detected were $78 \%(14 / 18)$ and $55 \%(6 / 11)$, respectively. Thus, in the majority of cases cervicitis and urethritis were caused by other agent(s) than $C$ trachomatis or $N$ gonorrhoeae. Mycoplasma genitalium may play a role in male urethritis, ${ }^{2021}$ but its role in cervicitis remains to be resolved.

We conclude that the Amplicor PCR can be used on ano-rectal and pharyngeal swab samples. Ano-rectal swab samples should be obtained from females and homosexual males at high risk of infection. Pharyngeal swab samples should be taken from females at high risk of infection, especially when pharyngeal signs or symptoms are present.

1 Østergaard L, Traulsen J, Birkelund S, Christiansen G. Evaluation of urogenital Chlamydia trachomatis infections by cell culture and the polymerase chain reaction using a closed system. Eur $\mathcal{F}$ Clin Microbiol Infect Dis 1991;10: closed syste

2 Brunham RC, Paavonen J, Stevens CE, Kiviat N, Kuo CC, Critchlow CW, et al. Mucopurulent cervicitis-the ignored counterpart in women of urethritis in men. $N$ Engl f Med 1984;311:1-6.

3 Cates W, Wasserheit $\mathrm{JN}$. Genital chlamydial infections: epidemiology and reproductive sequelae. Am $\mathcal{f}$ Obstet Gynecol 1991;164:1771-81.

4 Martin DH, Mroczkowski TF, Dalu ZA, McCarty J, Jones RB, Hopkins SJ, et al. A controlled trial of a single dose of azithromycin for the treatment of chlamydial urethritis and cervicitis. N Engl F Med 1992;327:921-5.

5 Jones RB, Rabinovitch RA, Katz BP, Batteiger BE, Quinn TS, Terho $\mathrm{P}$, et al. Chlamydia trachomatis in the pharynx and rectum of heterosexual patients at risk for genital infection. Ann Intern Med 1985;102:757-62.

6 Sulaiman MZ, Foster J, Pugh SF. Prevalence of Chlamydia trachomatis infection in homosexual men. Genitourin Med trachomatis infection

7 McMillan A, Sommerville RG, McKie PMK. Chlamydial infection in homosexual men; frequency of isolation of Chlamydia trachomatis from the urethra, ano-rectum, and pharynx. Br ₹ Vener Dis 1981;57:47-9.

8 Quinn TC, Goodell SE, Mkrtichian E, Schuffler MD, Wang SP, Stamm WE, et al. Chlamydia trachomatis proctitis. N Engl F Med 1981;305:195-200.

9 Munday PE, Carder JM, Taylor-Robinson D. Chlamydial proctitis? Genitourin Med 1985;61:376-8.

10 Rompalo AM, Price CB, Roberts PL, Stamm WE Potential value of rectal-screening cultures for Chlamydia trachomatis in homosexual men. F Infect Dis 1986;153: trachoma 888 .

11 Workowski KA, Lampe MF, Wong KG, Watts MB, Stamm WE. Long-term eradication of Chlamydia trachomatis genital infection after antimicrobial therapy. Evidence against persistent infection. $\mathcal{F} A M A$ 1993;270 2071-5.

12 Jebakumar SPR, Storey C, Lusher M, Nelson J, Goorney $B$, Haye KR. Value of screening for oro-pharyngeal Chlamydia trachomatis infection. F Clin Pathol 1995;48 658-61.

13 Kessler HH, Pierer K, Stuenzner D, Auer-Grumbach P, Haller EM, Marth E. Rapid detection of Chlamydia trachomatis in conjunctival, pharyngeal, and urethral specimens with a new polymerase chain reaction assay. Sex Transm Dis 1994;21:191-5.

14 Tabrizi SN, Chen S, Borg AJ, Lees MI, Fariley CK, Jackson HD, et al. Patient-administered tampon-collected genital cells in the assessment of Chlamydia trachomatis infection using polymerase chain reaction. Sex Transm Dis 1996;23:494-7.

15 Lee HH, Chernesky MA, Schachter J, Burczak JD Andrews WW, Muldoon S, et al. Diagnosis of Chlamydia trachomatis genitourinary infection in women by ligase chain reaction assay of urine. Lancet 1995;345:213-6.

16 Östergaard L, Møller JK, Andersen B, Olesen F. Diagnosis of urogenital Chlamydia infection in women based on mailed samples obtained at home: multipractice comparmailed samples obtained at home:

17 Workowski KA, Stevens CE, Suchland RJ, Holmes KK, Eschenbach DA, Pettinger MB, et al. Clinical manifestations of genital infection due to Chlamydia trachomatis in tions of genital infection due to Chlamydia trachomatis in women: differen

18 Quinn TC, Gaydos C, Mary S, Bobo L, Hook III E Wiscidi R, Rompalo A. Epidemiologic and microbiologic correlates of Chlamydia trachomatis infection in sexual partnerships. FAMA 1996;276:1737-42.

19 Worm AM, Petersen CS. Transmission of chlamydial infections to sexual partners. Genitourin Med 1987;63: 19-21.

20 Jensen JS, Orsum R, Dohn B, Uldum S, Worm AM, LindK. Mycoplasma genitalium: a cause of male urethritis? Genitourin Med 1993;69:265-9.

21 Horner PJ, Gilroy CB, Thomas BJ, Naidoo RO, TaylorRobinson D. Association of Mycoplasma genitalium with acute non-gonococcal urethritis. Lancet 1993;342:582-5. 